\title{
Removing Regional Trends in Microgravity in Complex Environments: Testing on 3D Model and Field Investigations in the Eastern Dead Sea Coast (Jordan)
}

\author{
A. Al-Zoubi, ${ }^{1}$ L. Eppelbaum, ${ }^{2}$ A. Abueladas, ${ }^{1}$ M. Ezersky, ${ }^{3}$ and E. Akkawi ${ }^{1}$ \\ ${ }^{1}$ Al-Balqa Applied University, Salt 19117, Jordan \\ ${ }^{2}$ Department of Geophysical, Atmospheric and Planetary Sciences, Tel Aviv University, Ramat Aviv, Tel Aviv 69978, Israel \\ ${ }^{3}$ Geophysical Institute of Israel, P.O. Box 182, Lod 71100, Israel
}

Correspondence should be addressed to L. Eppelbaum; levap@post.tau.ac.il

Received 29 September 2012; Accepted 18 January 2013

Academic Editor: Umberta Tinivella

Copyright (C) 2013 A. Al-Zoubi et al. This is an open access article distributed under the Creative Commons Attribution License, which permits unrestricted use, distribution, and reproduction in any medium, provided the original work is properly cited.

\begin{abstract}
Microgravity investigations are now recognized as a powerful tool for subsurface imaging and especially for the localization of underground karsts. However numerous natural (geological), technical, and environmental factors interfere with microgravity survey processing and interpretation. One of natural factors that causes the most disturbance in complex geological environments is the influence of regional trends. In the Dead Sea coastal areas the influence of regional trends can exceed residual gravity effects by some tenfold. Many widely applied methods are unable to remove regional trends with sufficient accuracy. We tested number of transformation methods (including computing gravity field derivatives, self-adjusting and adaptive filtering, Fourier series, wavelet, and other procedures) on a 3D model (complicated by randomly distributed noise), and field investigations were carried out in Ghor Al-Haditha (the eastern side of the Dead Sea in Jordan). We show that the most effective methods for regional trend removal (at least for the theoretical and field cases here) are the bilinear saddle and local polynomial regressions. Application of these methods made it possible to detect the anomalous gravity effect from buried targets in the theoretical model and to extract the local gravity anomaly at the Ghor Al-Haditha site. The local anomaly was utilized for 3D gravity modeling to construct a physical-geological model $(P G M)$.
\end{abstract}

\section{Introduction}

The development of new modern gravimetric and variometric (gradientometric) equipment, which makes it possible to record small previously inaccessible anomalies, has enhanced observational methodology as well as new gravity data processing methods and interpretation. These advances have triggered the rapid rise in the number of microgravity methodology applications in environmental and economic minerals geophysics.

Microgravity is now recognized as an effective tool for the analysis of a whole range of geological subsurface inhomogeneities, the monitoring of volcanic activity, and prospecting for useful minerals (e.g., [1-34]).

At the same time different kinds of noise of different origin complicate analysis of microgravity data. For removing (elimination) the noise components numerous procedures and methodologies were developed. We will analyze in this paper a problem of regional trend removing under complex geological-geophysical environments. Such a problem is highly essential by delineation of weak anomalies from buried karst terranes in the Dead Sea Basin where regional horizontal gravity gradients may exceed values of $10 \mathrm{mGal} / \mathrm{km}$.

\section{A Brief Review of Microgravity Investigations in Subsurface Studies}

Colley [2] apparently was the first to apply the gravity method for cave delineation. Despite the fact that the accuracy of gravity observations at that time was not sufficiently precise, he presented some examples of typical negative gravity anomalies in large caverns in Iraq. 


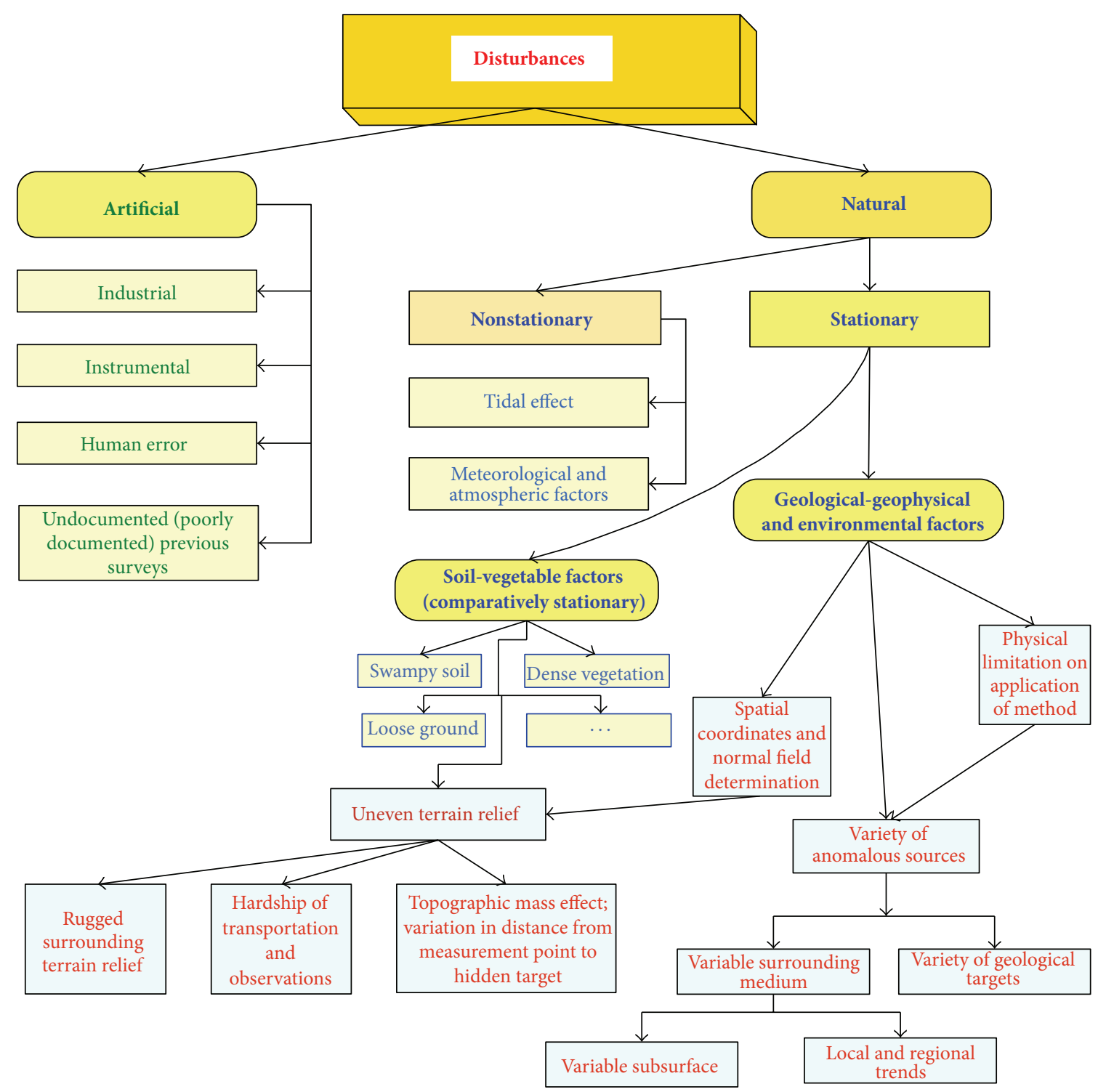

FIGURE 1: Noise affecting microgravity investigations (adapted from [45]).

Fajklewicz [4] examined the vertical gravity gradient $\left(W_{z z}\right)$ over underground galleries. He was probably the first to note a significant difference between the physically measured $W_{z z}$ and this value obtained by transformation. Interesting examples of microgravity anomalies from archaeological targets are presented in Bližkovský [5]. Butler [7] showed that microgravity measurements could be used to detect and delineate the main components of complex underground cavity systems. He computed the second and third derivatives of the gravity potential and polynomial surface to develop the initial physical-geological models (PGMs). Butler [8] surveyed gravity and gravity-gradient determination concepts and their corresponding interpretative microgravity procedures.

A nonconventional attempt to use microgravity observations for weight determination of stockpiled ore was reported by Sjostrom and Butler [35] who estimated the mass of many chromite and other ore bodies noninvasively.

Crawford [12] employed microgravity to detect sinkhole collapses under highways in the USA. Elawadi et al. [36] showed that the application of well-known neural network procedures could increase the assessment effectiveness of the depth and radius of subsurface cavities revealed by microgravity data. Rybakov et al's [15] work triggered the use of microgravity to find sinkholes in the complex geological conditions of the Dead Sea coastal plain.

Types of noise (disturbances) arising in microgravity investigations were studied in detail in Debeglia and Dupont [37]. Styles et al. [18] discussed the key problems related to the removal of noise components in microgravity in complex environments. 

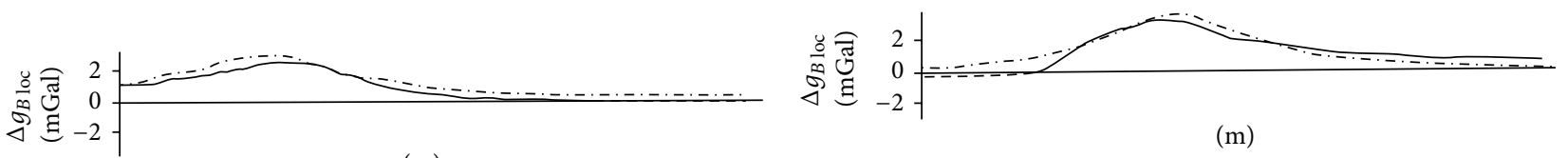

$(\mathrm{m})$
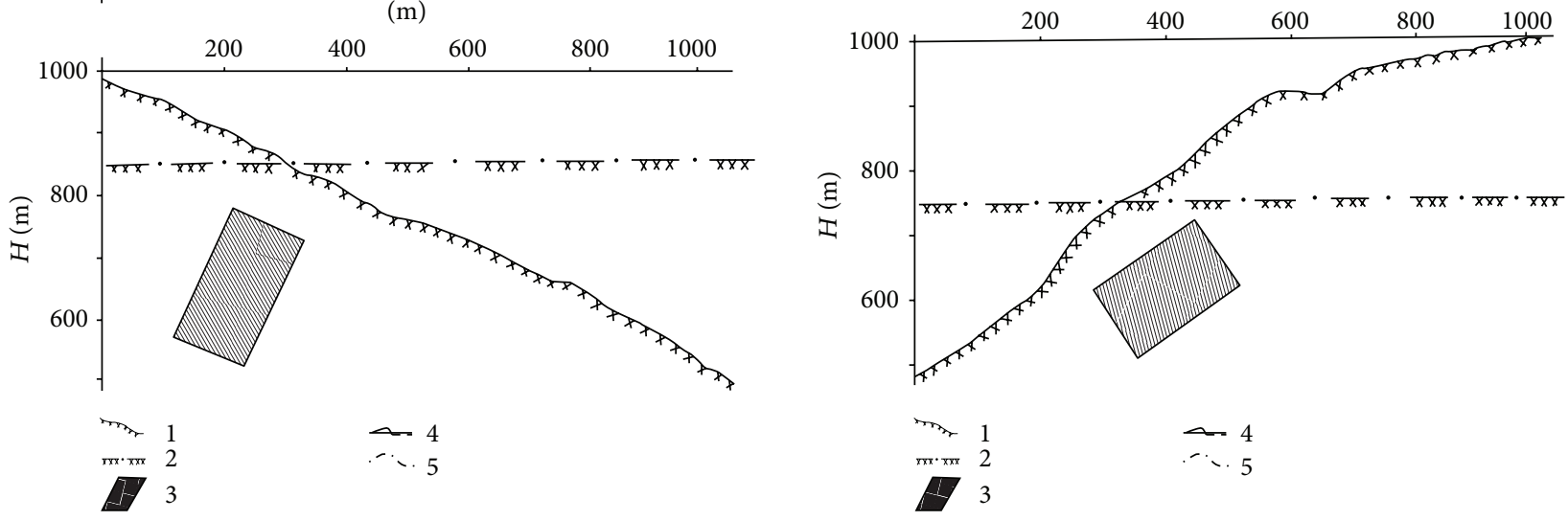

(a)

(b)

FIGURE 2: Negative effect of gravitational anomalies from a local anomalous body observed on inclined and horizontal profiles (after [46], with modifications). (a) Smooth slope, (b) complicated slope. (1) Inclined profile; (2) horizontal profile; (3) anomalous body with a positive contrast density $\Delta \sigma=1500 \mathrm{~kg} / \mathrm{m}^{3}$; anomaly $\Delta g_{B}$ from the same body after topographic mass attraction correction: (4) on an inclined profile, (5) on a horizontal profile.

The need for additional computation of the surrounding terrain relief by $3 \mathrm{D}$ gravity modeling in ore deposits occurring in the very complex topography of the Greater Caucasus was discussed in Eppelbaum and Khesin [17].

Abad et al. [23] carried out an assessment of a buried rainwater cistern in a Carthusian monastery (Valencia, Spain) by $2 \mathrm{D}$ microgravity modeling. Microgravity monitoring is one of the most widely used geophysical techniques for predicting volcanic activity; for instance, Carbone and Greco [38] described in detail their microgravity monitoring of Mt. Etna.

Advanced methods in magnetic prospecting can be adapted to quantitative analysis of microgravity anomalies in complex environments [25]. Eppelbaum et al. [1] described various transformation methods to identify buried sinkholes including 3D gravity modeling to develop a PGM of Nahal Never South in the western Dead Sea coast.

Deroussi et al. [27] applied precise gravity investigations for delineating cavities and large fractured zones by planning road construction in lava flow after recent volcano eruption in Réunion island. Microgravity combined with absolute gravity measurements has also been used to study water storage variations in a karst aquifer on the Larzac Plateau (France) [39]. Castiello et al. [40] reported a microgravity studying an ancient underground cavity in the complex urban environment of Naples.

Types of noise associated with microgravity studies of shallow karst cavities in areas of developed infrastructure are presented in detail in Leucci and Georgi [30]. Porzucek [41] discusses the advantages and disadvantages of using the Euler deconvolution in microgravity studies. A new method for the simultaneous, nonlinear inversion of gravity changes and surface deformation using bodies with a free geometry was proposed by Camacho et al. [31].

The importance of gravity field observations at different levels as well as the precise calculation of topographic effects in intermediate and distant zones was analyzed in Eppelbaum [32]. Dolgal and Sharkhimullin [42] suggested using a "localization function" to enhance the quality of PGMs and reduce the ambiguity of the results in high-precise gravity.

Kaufmann et al. [43] successfully employed microgravity to identify subsurface voids in the Unicorn cave in the Harz Mountains (Germany). Hajian et al. [33] applied locally linear neurofuzzy microgravity modeling to the three most common shapes of subsurface cavities: sphere, vertical cylinder, and horizontal cylinder. The authors showed that their method can estimate cavity parameters more accurately than least-squares minimization or multilayer perceptron methods.

Panisova et al. [44] fruitfully applied a new modification of close range photogrammetry for calculation of building corrections in the microgravity survey for karst delineation in the area of historical edifice (Slovakia).

\section{Different Kinds of Noise in Microgravity Surveys}

A microgravity survey is the geophysical method most affected by corrections and reductions caused by different kinds of noise (disturbances). A chart showing the different types of noise typical to microgravity studies is presented in Figure 1.

These types of noise are described in more detail below. 


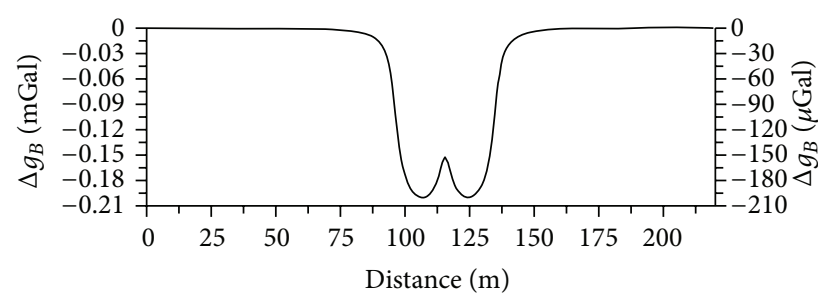

(a)

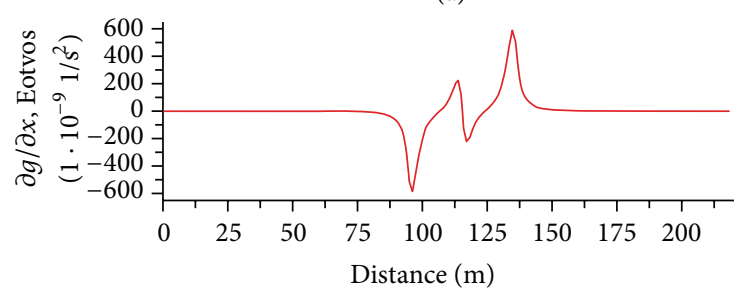

(b)

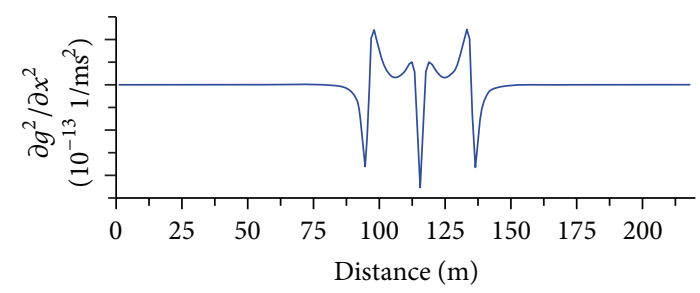

(c)

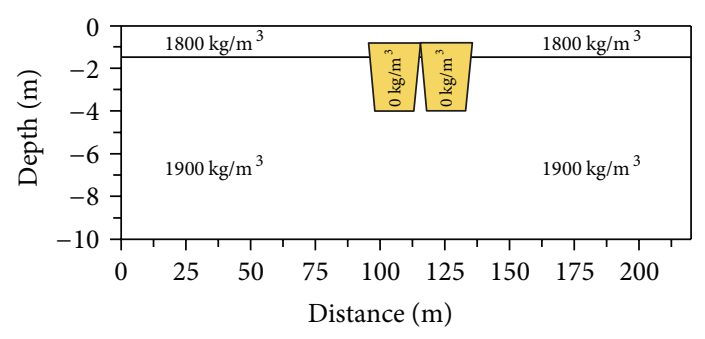

(d)

FIGURE 3: Computation of the horizontal derivatives of the gravity field for two proximal sinkhole models. (a) Computed gravity curve (level of computation: $0.3 \mathrm{~m}$ ), (b) first horizontal derivative of gravity field $\Delta g_{x}$, (c) second horizontal derivative $\Delta g_{x x}$, and (d) physicalgeological model (after [1]).

3.1. Artificial (Man-Made) Noise. The industrial component of noise mainly comes from surface and underground constructions, garbage dumps, transportation and communications lines, and so forth. The instrumental component is associated with the technical properties of gravimeters (e.g., shift zero) and gradientometers. Human error, obviously, can accompany geophysical observations at any time. Finally, undocumented (poorly documented) results of previous surveys can distort preliminary $P A M$ development.

3.2. Natural Disturbances. Nonstationary noise includes, for instance, known tidal effects. Meteorological conditions (rain, lightning, snow, hurricanes, etc.) can also affect gravimeter readings. Corrections for the atmosphere deserve special attention in microgravity investigations, since the air layer attraction is different at various levels over and below the m.s.l. Soil-vegetation factors associated with certain soil types (e.g., swampy soil or loose ground in deserts) and dense vegetation, which sometimes hampers movement along the profile, also need to be taken into account.

3.3. Geological-Geophysical and Environmental Factors. These constitute the most important physical-geological disturbances. The application of any geophysical method depends primarily on the existence of physical properties contrast between the objects under study and the surrounding medium. The physical limitation of method application assesses the measurable density contrast properties between the anomalous targets and the host media.

3.4. Spatial Coordinates and Normal Gravity Field Determination. Spatial coordinates and normal gravity field determination are also crucial to precise gravity studies and any inaccuracies here may lead to significant errors in subsequent analyses.

3.5. Uneven Terrain Relief. Uneven terrain relief can hamper the movement of equipment and restrict gravity data acquisition. Physically, the gravity field is affected by the form and density of the topographic features composing the relief, as well as variations in the distance from the point of measurement to the hidden target [32]. Calculations for the surrounding terrain relief (sometimes for radii up to $200 \mathrm{~km}$ ) are also of great importance $[47,48]$.

3.6. Earthquake Damage. Earthquake damage zones are widely spread over the Eastern Mediterranean, especially in the regions near the Dead Sea Transform (DST) Zone [49]. These zones may significantly complicate microgravity data analysis.

3.7. The Variety of Anomalous Sources. The variety of anomalous sources is composed of two factors: the variable surrounding medium and the variety of anomalous targets. Both these factors are crucial and greatly complicate the interpretation of magnetic data.

3.8. Variable Subsurface. Variable subsurface can make it difficult to determine the correct densities of bodies occurring close to the earth's surface.

3.9. Local and Regional Trends. Local and regional trends (linear, parabolic, or other types) often mask the target gravity effects considerably (e.g., [46-48, 50]). Sometimes regional gravity trend effects may exceed local desired anomalies by some tenfold.

Let us consider the last disturbing factor in detail. The correct removal (elimination) of regional trends is not a trivial task (e.g., [47]). Below we present two examples showing disturbing trend effects in detailed gravity investigations. Figure 2 shows two cases of nonhorizontal gravity observations with the presence of an anomalous body. The distorting effect of a nonhorizontal observation line occurs 


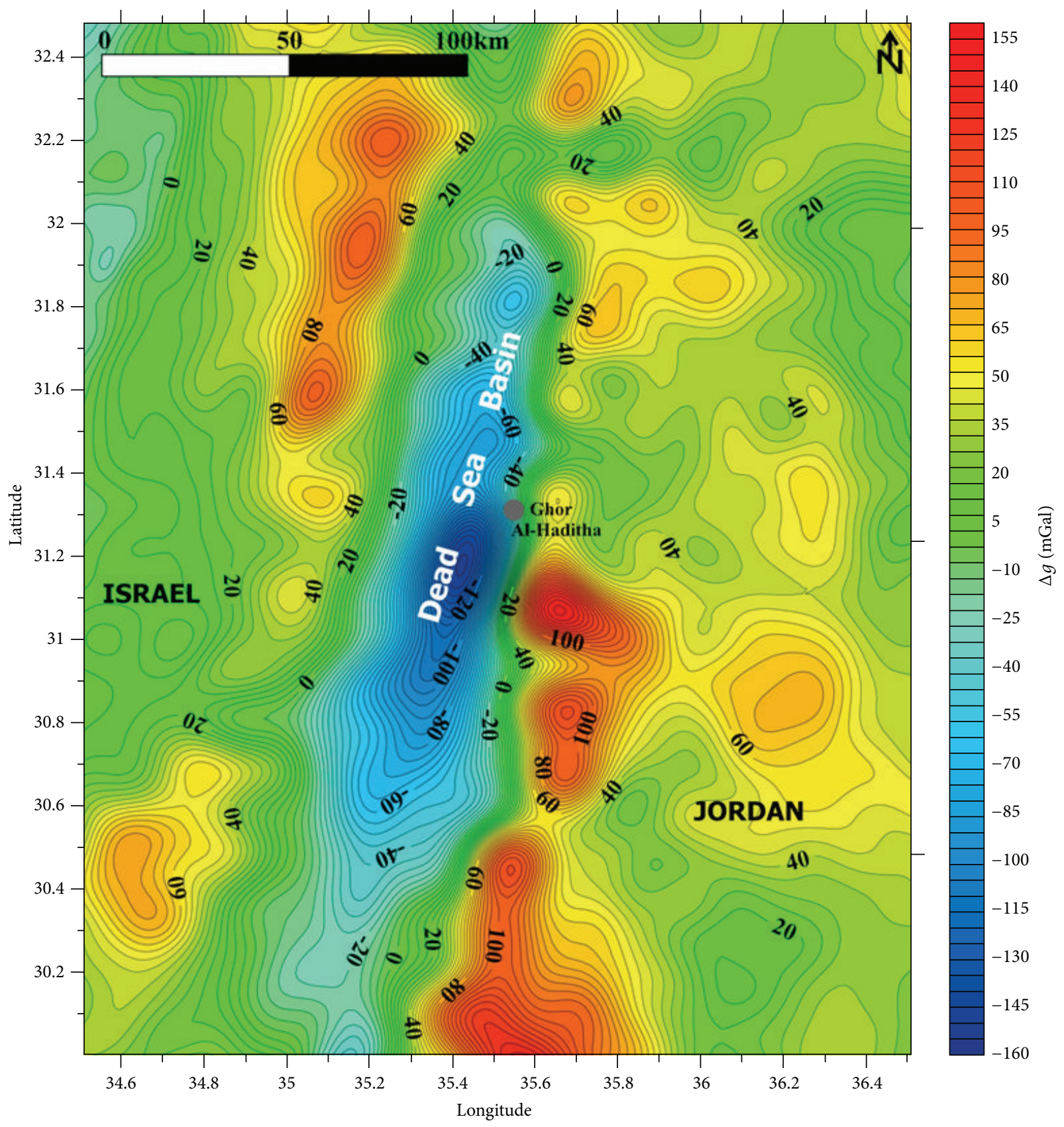

FIgURE 4: Areal map of the investigated site.

when the target object differs from the host medium by a contrast density and produces an anomalous vertical gradient. Comparing the $\Delta g_{B}$ anomalies from the local body observed on the inclined and horizontal relief indicates that the gravity effects in these situations are different (Figure 2). Despite the fact that all the necessary corrections were applied to the observations on the inclined relief, the computed Bouguer anomaly is characterized by small negative values (minimum) in the downward direction of the relief, whereas the anomaly on the horizontal profile has no negative values (this kind of noise is described in Section 3.5). Thus, applying all conventional corrections does not eliminate this trend because the observation point for the anomalous object was different [46]. Hence a special methodology is required for gravimetric quantitative anomaly interpretation in conditions of inclined relief [32].

Sometimes even simple computing of the first and second derivatives of the gravity field $\Delta g_{x}$ and $\Delta g_{x x}$ (second and third derivatives of the gravity potential, resp.) is enough to locate local bodies against a disturbing field background. One such example is presented in Figure 3 where the Bouguer gravity $\Delta g_{B}$ is practically impossible to interpret, whereas the calculation of $\Delta g_{B x}$ was informative regarding the geometry of two closely occurring sinkholes. Finally, the behavior 


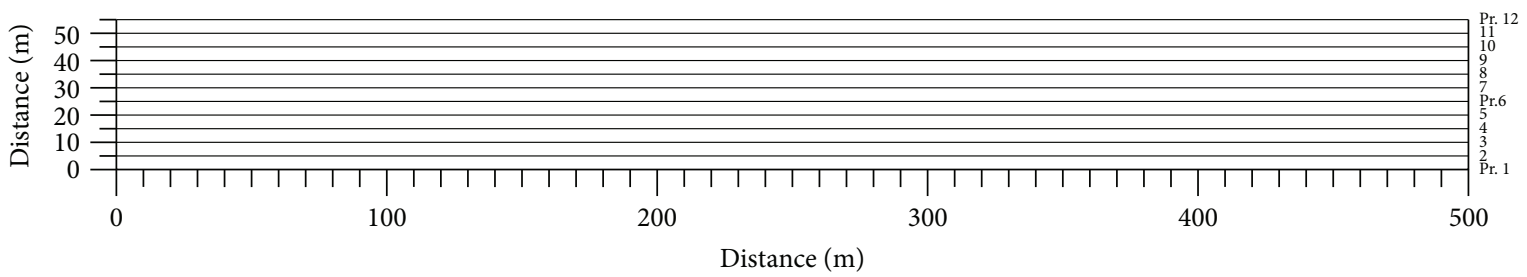

FIGURE 5: Scheme of gravity field 3D computation for the model example.

of the graph $\Delta g_{B x x}$ clearly reflects the location of the vertical boundaries of two closely occurring objects with a small negative interval (surrounding medium) between them.

The area under study-Ghor Al-Haditha-is situated in the eastern coastal plain of the Dead Sea (Jordan) in conditions of very complex regional gravity pattern (Figure 4). The satellite gravity data shown in this figure were obtained from the World Gravity DB as retracked from Geosat and ERS-1 altimetry [51]. These observations were made with regular global 1-minute grids that can differentiate these data from previous odd surface and airborne gravity measurements. This complex gravity field distribution in the vicinity of the area under study is caused mainly by the strong negative effect of the low density sedimentary associations and salt layers accumulated in the DST and also several other factors.

\section{Computation of the 3D Gravity Effect from Models of Sinkholes and the Dead Sea Transform}

To test methods of regional trend elimination, two theoretical PGMs-sinkhole PGM and DST PGM-were developed. The computed gravity effects from these PGMs were also artificially complicated by randomly distributed noise.

4.1. Computation of the 3D Gravity Effect from the Sinkhole PGM . To calculate the 3D gravity field, 12 parallel profiles with a distance between them of $5 \mathrm{~m}$ were applied (Figure 5). For the PGM a two layer $\left(\sigma_{1}=2000 \mathrm{~kg} / \mathrm{m}^{3}\right.$ and $\sigma_{2}=2100 \mathrm{~kg} / \mathrm{m}^{3}$, resp.) $P G M$ with two types of ellipsoidal sinkholes was constructed (Figure 6). The center of the first large sinkhole was located at a depth of $-60 \mathrm{~m}$ below the earth's surface in the second layer, with a contrast density of $-900 \mathrm{~kg} / \mathrm{m}^{3}$. The center of the second small sinkhole was located at a depth of $-20 \mathrm{~m}$ below the earth's surface in the first layer, with a contrast density of $-2000 \mathrm{~kg} / \mathrm{m}^{3}$. Profile 6 was selected as the central one, and the left and right ends of sinkhole 1 were defined as -30 and $+30 \mathrm{~m}$, and for sinkhole 2 as -12 and $+12 \mathrm{~m}$, respectively. For the $3 \mathrm{D}$ gravity field modeling of this and the following examples, mainly the GSFC program [17] software was employed. The number of computation points along the sinkholes PGM was chosen to be 200 , that is, every $2.5 \mathrm{~m}$.

The compiled gravity map for the 12 profiles for the sinkhole $P G M$ is shown in Figure 7. As can be seen from this
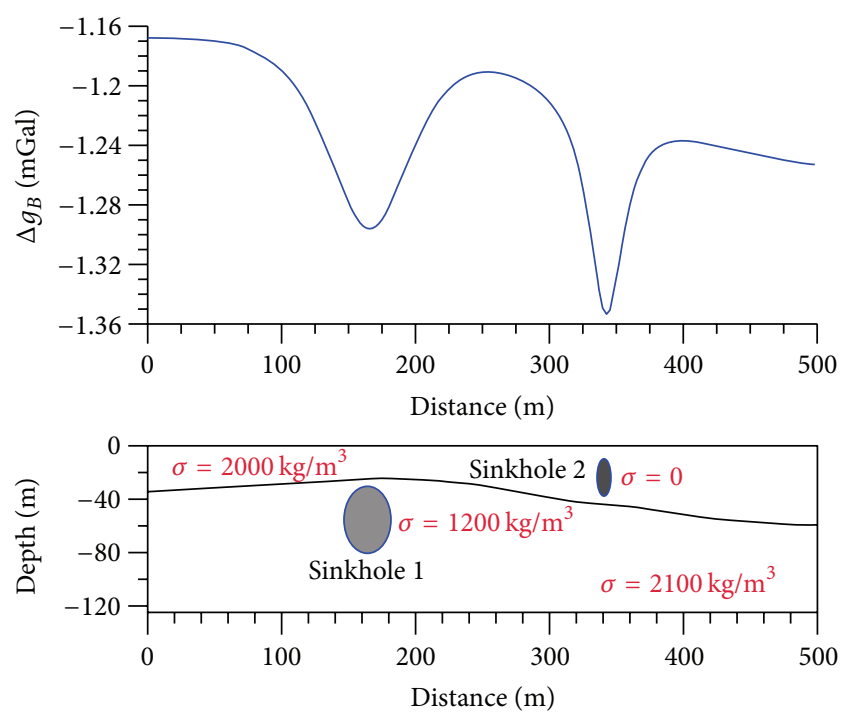

FIGURE 6: Gravity field anomalies along profile 6 from models of sinkholes.

map, the anomaly from sinkhole 2 is narrower than sinkhole 1 but is characterized by comparatively high amplitude.

4.2. Computation of the 3D Gravity Effect from the DST. The simplified PGM of the DST for its deepest part (Figure 8) was constructed from data presented in Ginzburg and BenAvraham [52], Weber et al. [53], and the authors' computations. The location of the sinkhole $500 \mathrm{~m}$ profile in the upper right section of the model is shown. The PGM of the DST was computed as the same for all 12 profiles. The computed gravity effect from the DST was added to the gravity field to account for the sinkhole PGM (Figure 9). As can be seen from this figure, the anomaly from sinkhole 2 can be visually detected, but the anomaly from sinkhole 1 is practically undetectable against the regional trend produced by the DST.

4.3. Noise Added by Random Number Generation. Given that the geological medium is usually more complex than presented in the models in Figures 6 and 8 we used a random number generator to introduce a noise factor into the calculations. Algorithms developed by Bichara et al. [6] and Wichura [54] were applied. The parameters of this randomly distributed noise-the mean values and the standard deviations along 12 profiles-are listed in Table 1. In other words, 


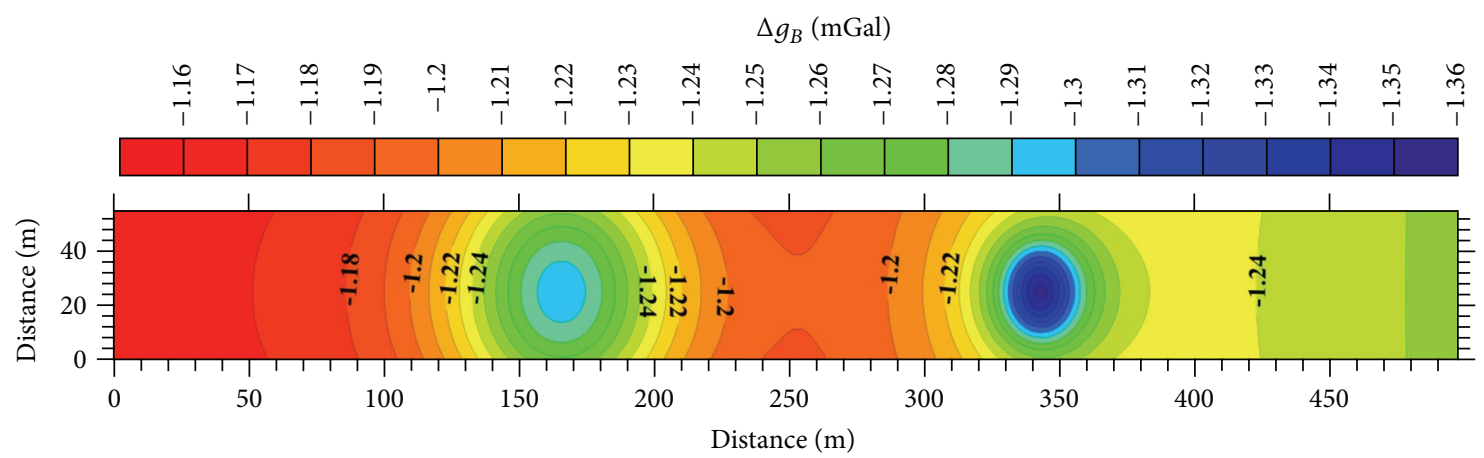

Figure 7: Compiled gravity map for 12 profiles.

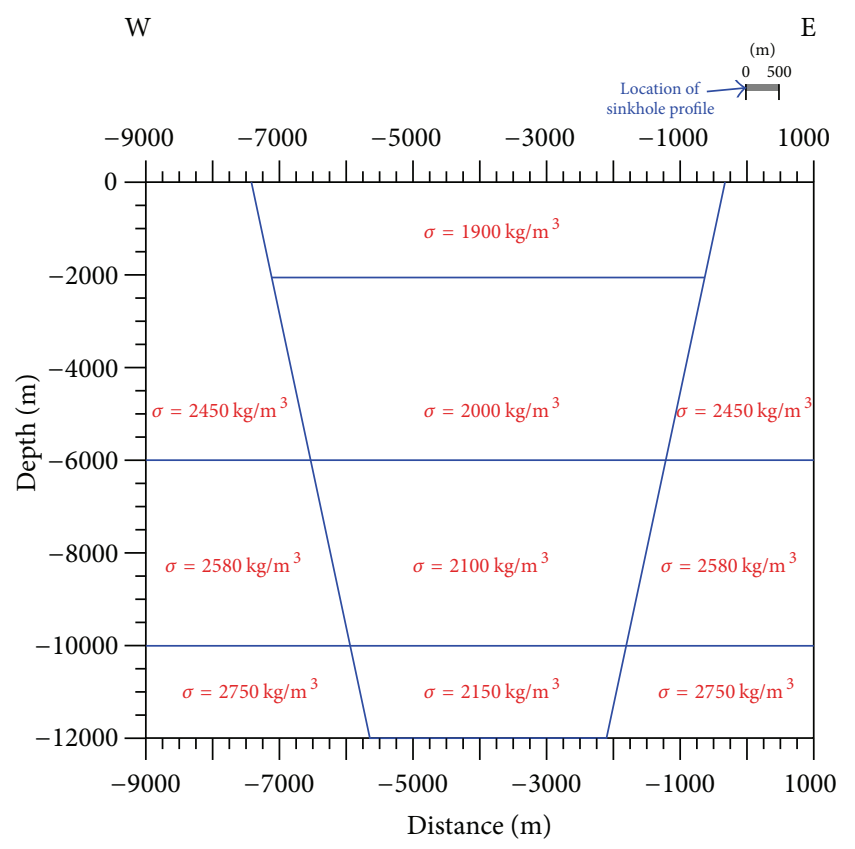

Figure 8: Simplified density-geological model of the Dead Sea Transform.

the randomly distributed nonrecurrent noise was added to 200 computation points for each of 12 profiles.

Figure 10 shows a gravity map compiled on the basis of randomly distributed noise (from Table 1). The combined gravity effects from (1) the sinkhole PGM, (2) the DST PGM, and (3) randomly distributed noise were used to compute the integrated gravity map that sums the effects of these three factors (Figure 11). It should be noted that in the map (Figure 11) there are no visual signatures of the negative anomalies from sinkholes 1 and 2.

\subsection{Results of the Different Algorithms to Eliminate Regional} Trends. To remove the regional trends, different algorithms and methods were applied: the first and second derivatives, self-adjusting and adaptive filtering, Fourier series, wavelet
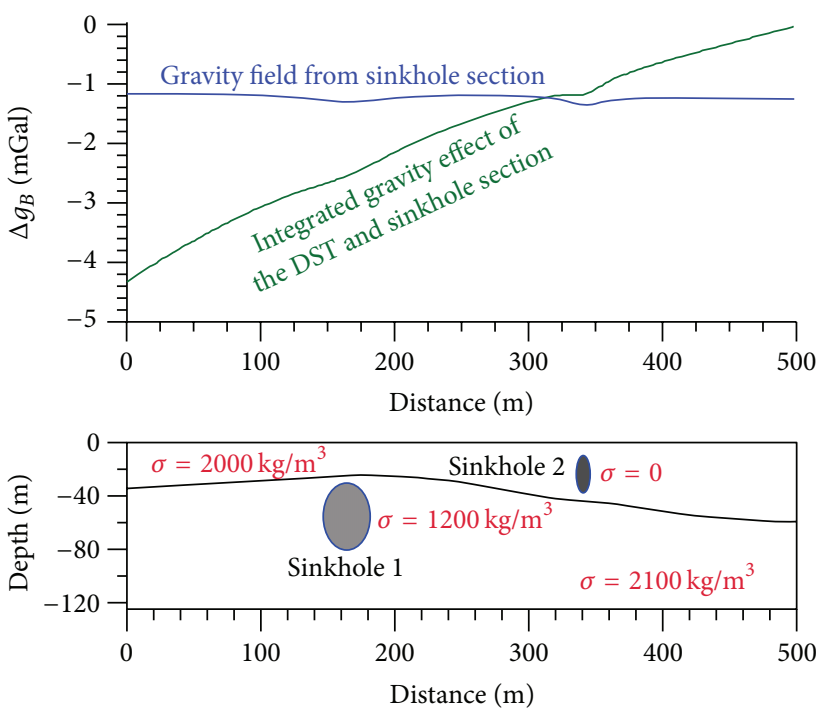

FIgURE 9: Combined gravity field along profile 6 from models of sinkholes and effect of the DST.

TABLE 1: Inserted randomly distributed noise.

\begin{tabular}{lcc}
\hline Profile number & Mean value & Standard deviation \\
\hline 1 & 0.150 & 0.040 \\
2 & 0.160 & 0.030 \\
3 & 0.140 & 0.035 \\
4 & 0.130 & 0.038 \\
5 & 0.170 & 0.029 \\
6 & 0.120 & 0.033 \\
7 & 0.150 & 0.038 \\
8 & 0.140 & 0.032 \\
9 & 0.110 & 0.024 \\
10 & 0.160 & 0.031 \\
11 & 0.125 & 0.025 \\
12 & 0.15 & 0.028 \\
\hline
\end{tabular}

decomposition, principal component analysis, inverse probability, and other methods were applied (altogether more than 30 different procedures). 


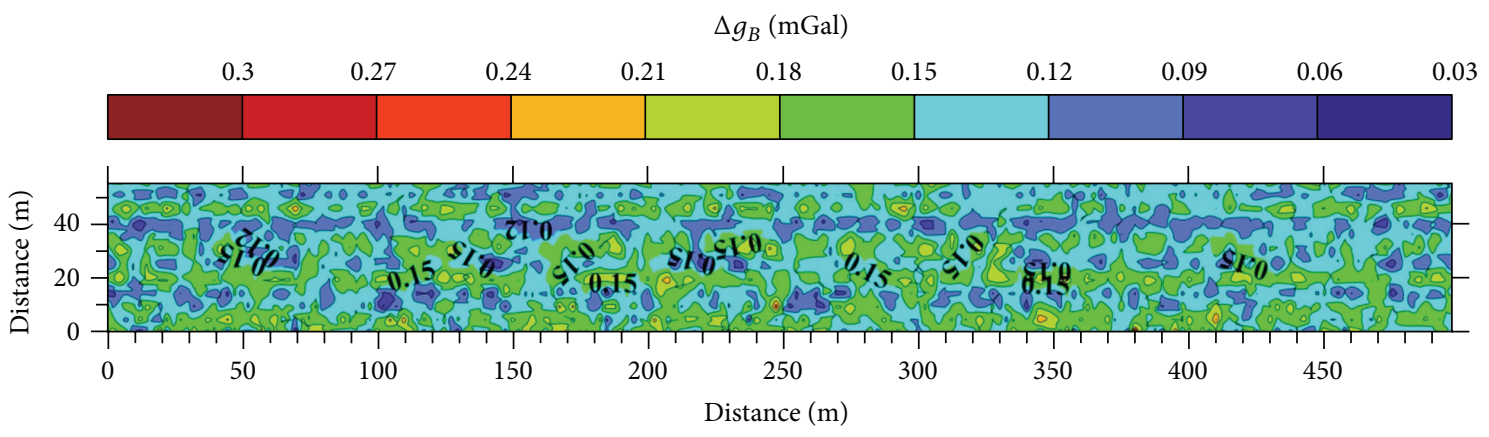

FIGURE 10: Compiled gravity map of the random noise for 12 profiles.

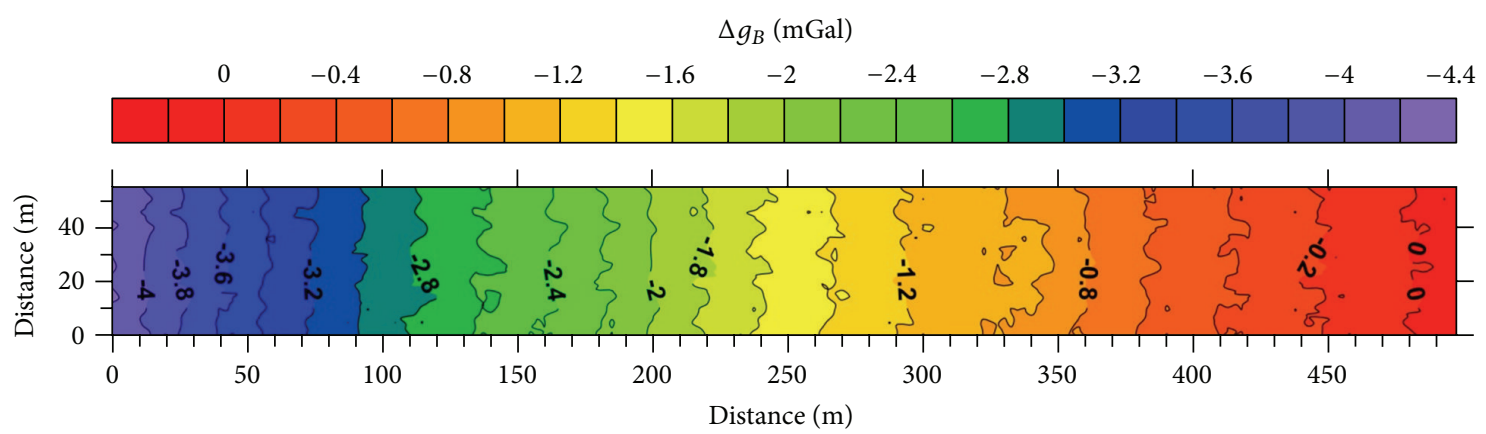

FIGURE 11: Compiled gravity map for 12 profiles with combined effect from: (1) the DST, (2) sinkholes, and (3) random noise.

Examples of applications of (1) the entropy parameter using a moving window with self-adapting size, (2) gradient sounding, and (3) power estimation by the Morlet transformation are presented in Figures 12(a), 12(b), and 12(c), respectively. Computing the entropy with the moving window (Figure 12(a)) revealed a clear ring anomaly from sinkhole 2 ; the anomaly from sinkhole 1 was difficult to locate. At the same time the boundary effect at the map edges (Figure 12(a)) complicated image reading. The results of gradient sounding (Figure 12(b)) suggested the presence of an anomaly from sinkhole 2. A power estimation based on a Morlet transformation (Figure 12(c)) very clearly indicates the location of sinkhole 2. However, a superposition of computed gravity anomalies and noise effects gives a false weak anomaly (located at 105-108 m) of sinkhole 1 .

Regression analysis is now considered one of the most powerful methods for removing trends of different kinds (e.g., [55-57]). Two regression methods were selected. Figure 13 shows the residual gravity map after subtracting a bilinear saddle $(F(x, y)=a+b x+c y+d x y)$ regression. The negative gravity anomaly from sinkhole 1 in the area of $160 \mathrm{~m}$ (see Figures 6 and 9) is clearly detected, whereas the negative anomaly from sinkhole 2 in the area of $340 \mathrm{~m}$ is small and could not be reliably detected.

The gravity map after subtracting a local polynomial regression $\left(F(x, y)=a+b x+c y+d x y+e x^{2}+f y^{2}\right)$ is presented in Figure 14. Here the negative anomaly from sinkhole 1 was weak and was difficult to detect, but the anomaly from sinkhole 2 was unmistakable. These findings suggest that there are advantages to using a combination of methods.

\section{Removing Regional Gravity Trend in the Area of Ghor Al-Haditha, on the Eastern Coastal Plain of the Dead Sea (Jordan)}

The Ghor Al-Haditha area is located south-east of the northern Dead Sea basin (see Figure 4). Alluvial fan deposits from Wadi Ibn Hammad cover the southern part of this area. Borehole sections indicate that the geological material of the shallow subsurface consists of laminated sand interbedded with layers of calcareous silts and possibly clay or marl. The sinkholes at the eastern coast of the Dead Sea can be dated to the mid-1980s [58].

The observed gravity map (Figure 15) shows the strong influence of the negative gravity effect due to the DST (and possibly other geological factors). Computing the first and second derivatives, self-adjusting filtering, gradient directional filtering, Fourier series, principal component analysis, and other methods were less successful than the bilinear saddle and local polynomial regressions.

Figure 16 displays results of the gradient sounding. After regional trend removal two local anomalies were found: one complex in the center of the area and the other near the western border. Clearly, however, this type of analysis is only valid for target qualitative delineation. 


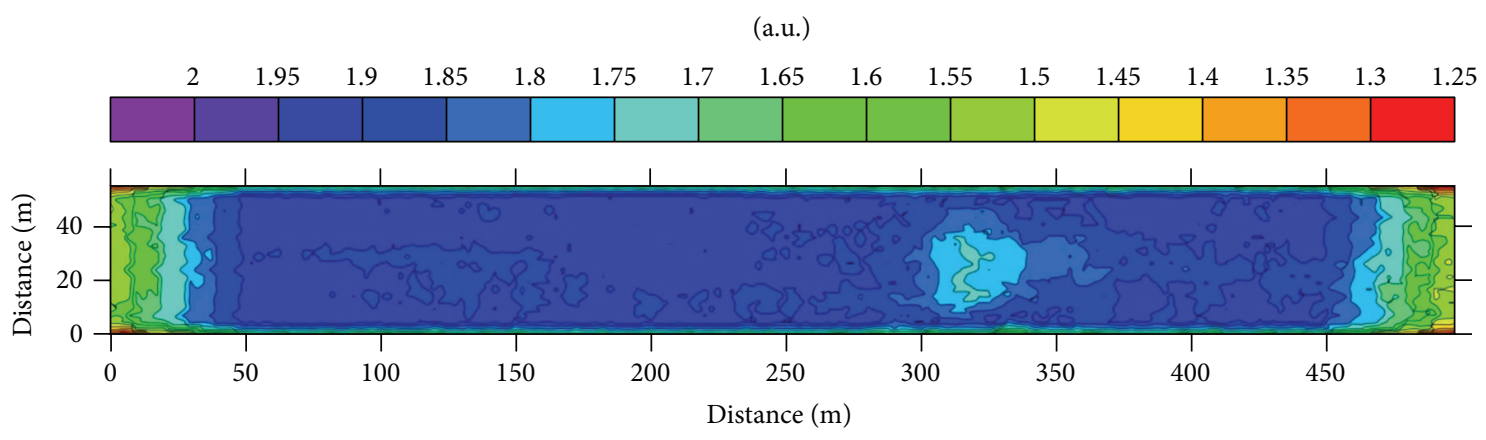

(a)

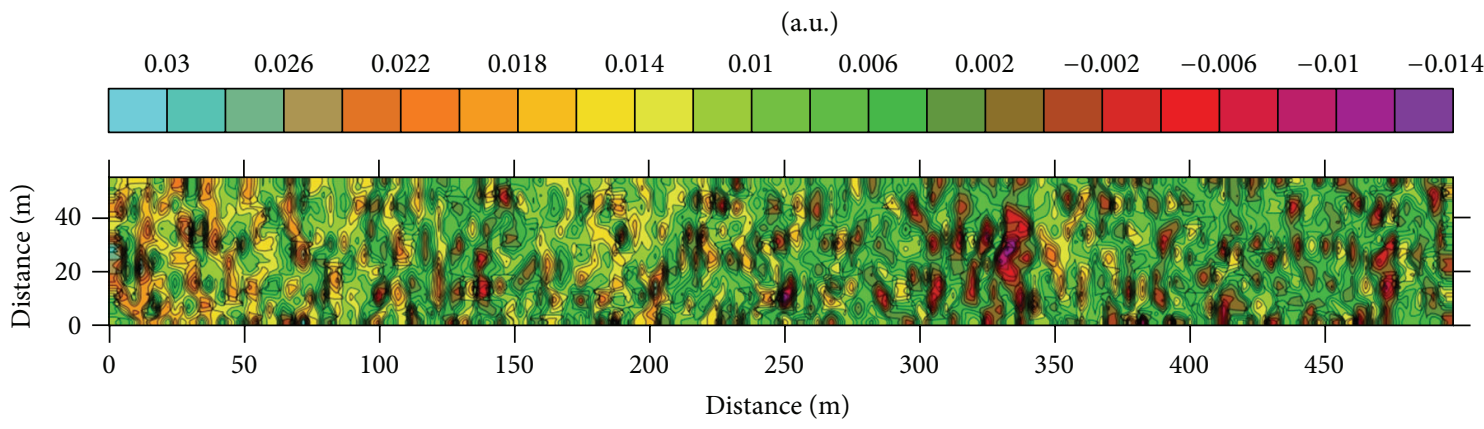

(b)

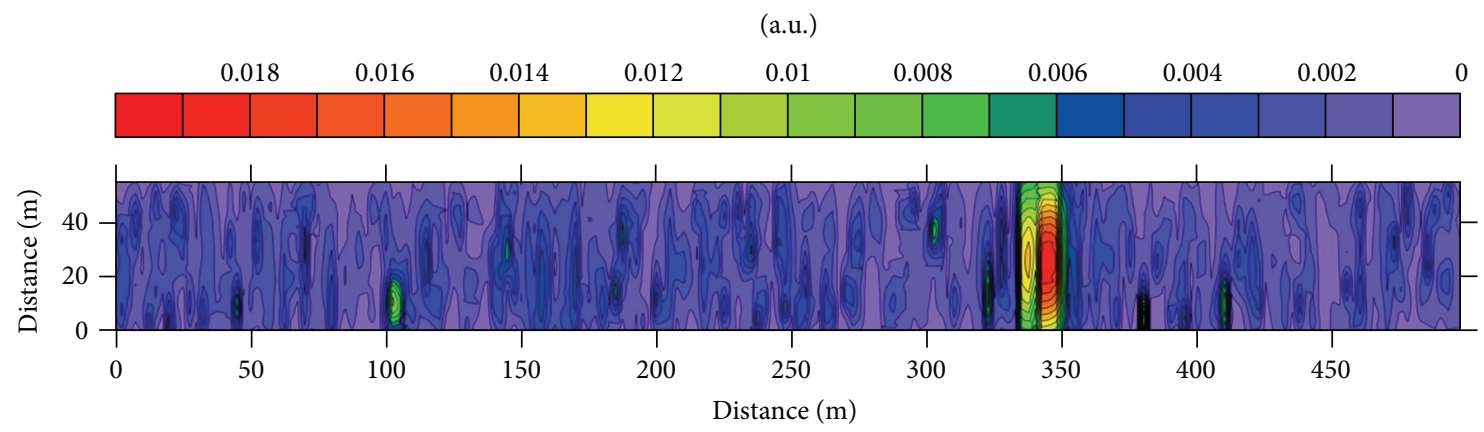

(c)

FIGURE 12: Results of three different methodologies: (a) entropy computation using a moving window with self-adapting size, (b) gradient sounding, and (c) power estimation by Morlet transformation.

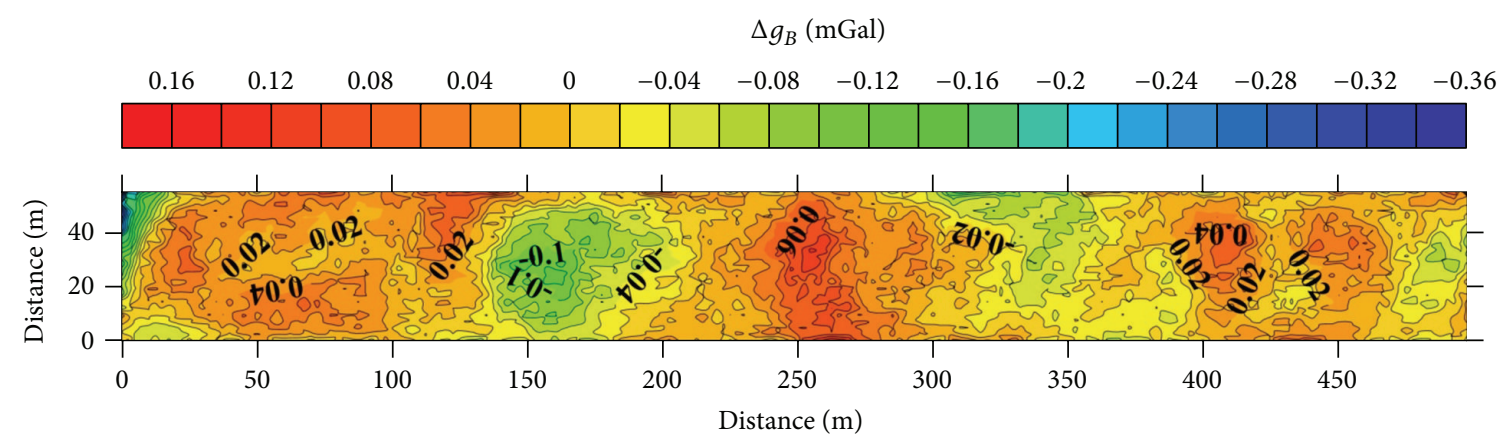

FIGURE 13: Residual gravity map after subtracting bilinear saddle regression.

A visual comparison of the residual maps (Figures 17 and 18 , resp.) shows the great similarity between the two regression methods. A negative anomaly in the center of the map with amplitude of $0.6-0.7 \mathrm{mGal}$ is very visible. An important advantage of the residual maps is that these maps can be used both for qualitative and quantitative analysis.

The gravity profiles are constructed along the same line (A-B in Figure 17) and $\left(\mathrm{A}^{\prime}-\mathrm{B}^{\prime}\right.$ in Figure 18) demonstrate 


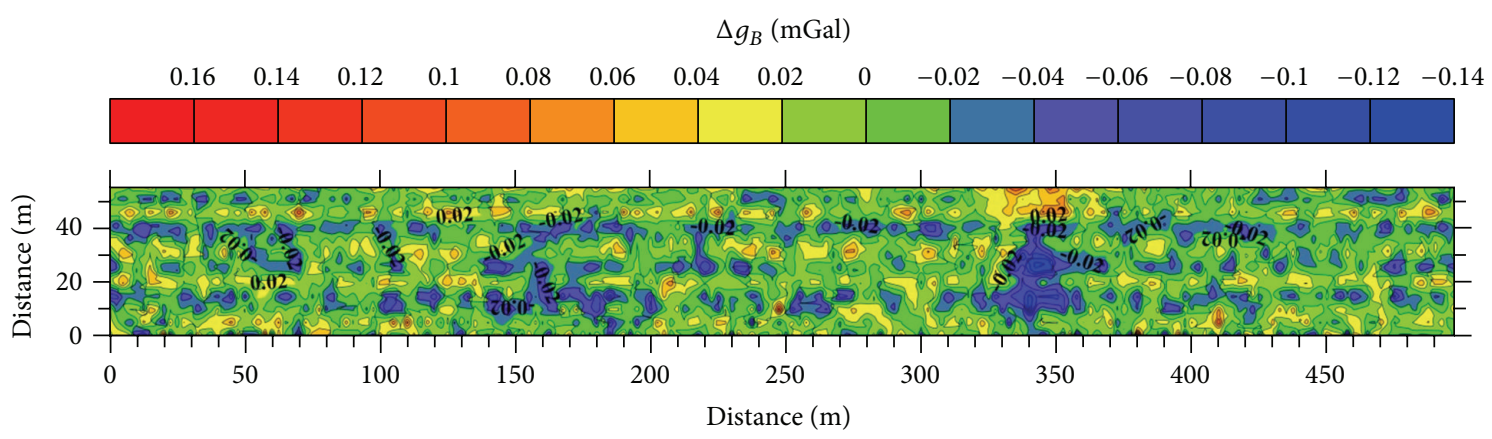

FIGURE 14: Residual gravity map after subtracting local polynomial.

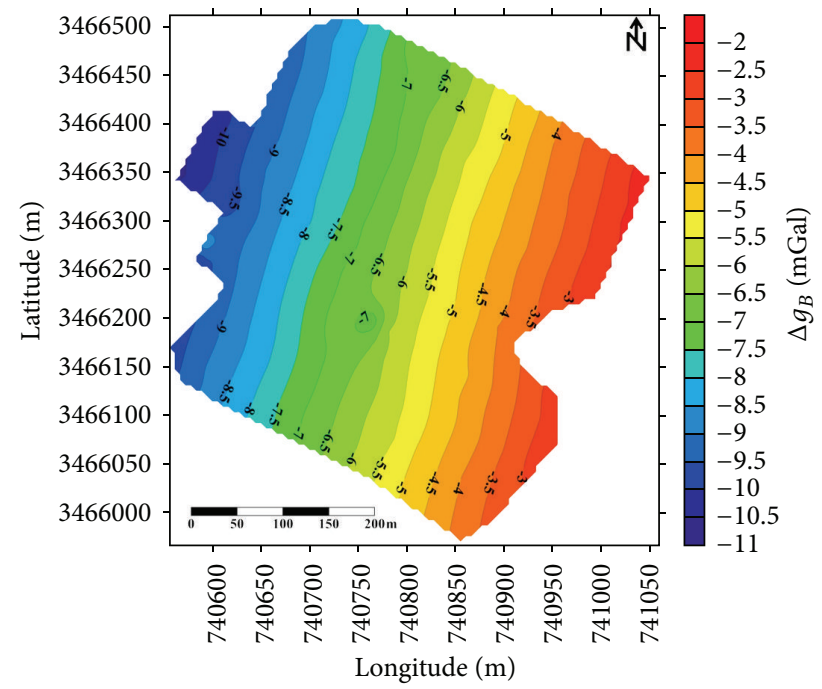

FIGURE 15: Bouguer gravity map of the Ghor Al-Haditha area (Jordan).

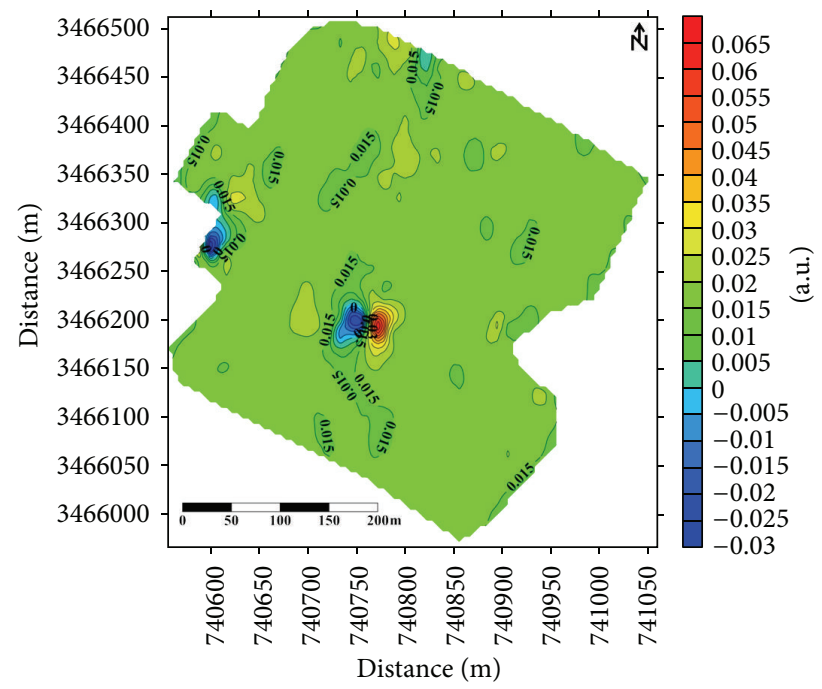

Figure 16: Results of gradient sounding.

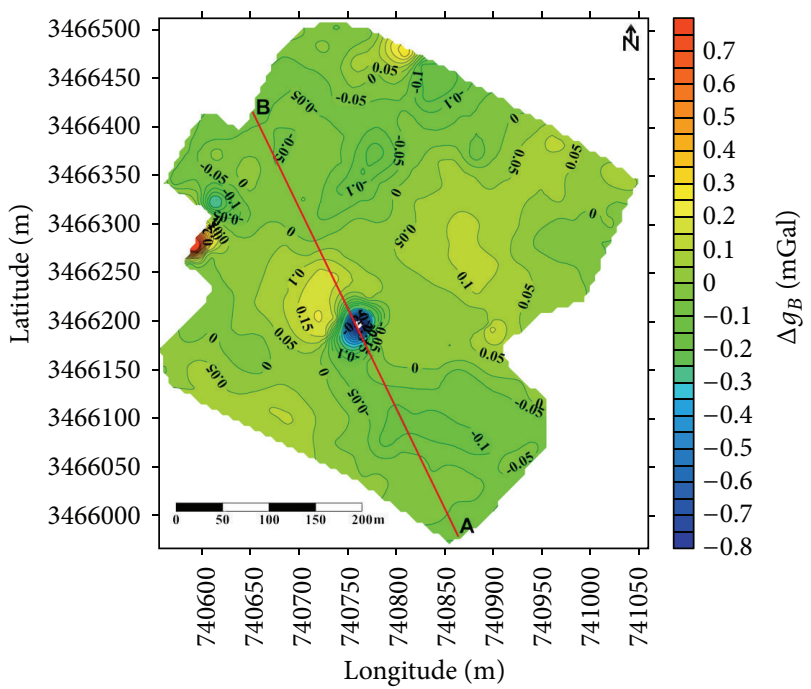

FIGURE 17: Residual gravity map of the Ghor Al-Haditha area after subtracting bilinear saddle regression.

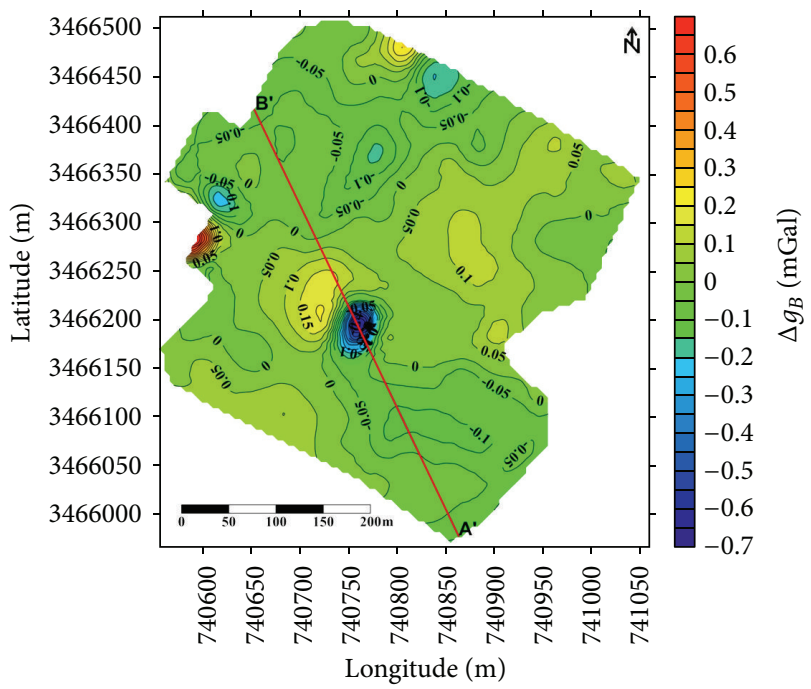

FIGURE 18: Residual gravity map of the Ghor Al-Haditha area after subtracting local polynomial. 


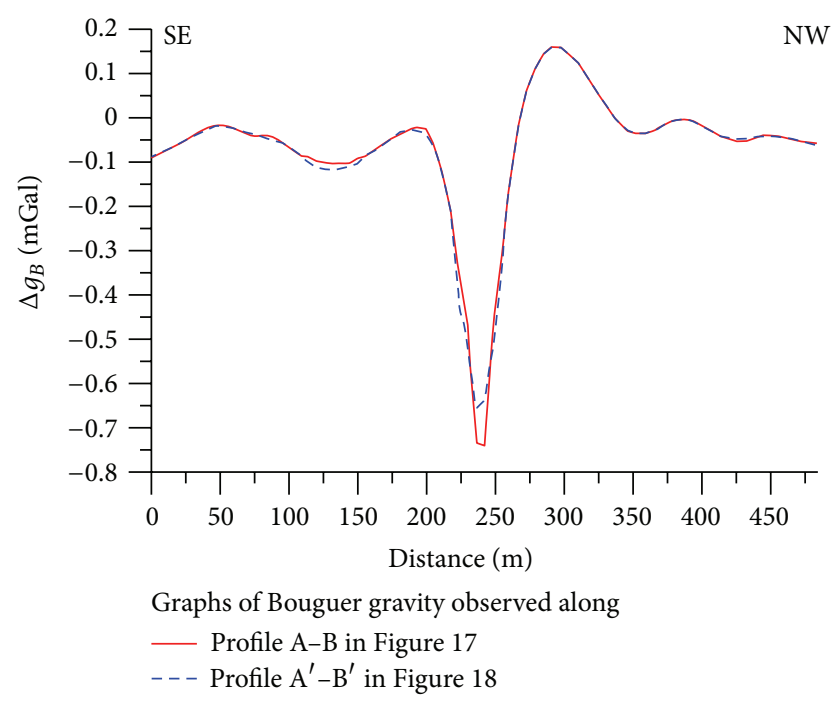

FIGURE 19: Comparison of gravity curves constructed along profile A-B for Figure 17 (after subtracting the bilinear saddle regression) and $\mathrm{A}^{\prime}-\mathrm{B}^{\prime}$ for Figure 18 (after subtracting the local polynomial).
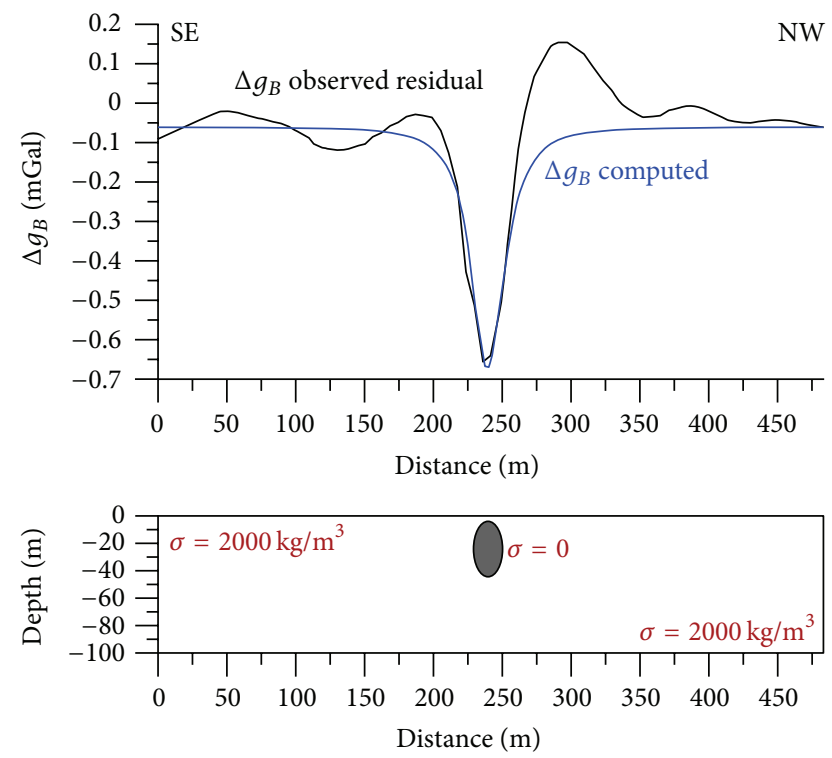

FIgURE 20: An initial physical-geological model along profile $\mathrm{A}^{\prime}-\mathrm{B}^{\prime}$ developed on the basis of 3D gravity field modeling.

(Figure 19) that there are some small differences, mainly in the amplitude value from the anomalous object with a negative density contrast.

$3 \mathrm{D}$ modeling indicates that such a gravity anomaly may have been produced by a sinkhole (similar to model 2 in Figure 6, but enlarged roughly twice) with its upper edge occurring at a depth of $4 \mathrm{~m}$ below the earth's surface (Figure 20). The location of this sinkhole and its size are consistent with the available geological data [59]. The disparity between the observed and computed $\Delta g_{B}$ in the right part of the profile may have been caused by the presence of an additional small underground cavity with an irregular shape.

\section{Conclusion}

The different kinds of noise affecting microgravity investigations amply illustrate the need for careful calculation of each of these disturbing factors. In particular, the influence of regional trends often masks the target local microgravity anomalies. The 3D theoretical PGM of sinkholes combined with the gravity effect from the DST (producing a strong regional trend) as well as the randomly distributed noise (introducing some geological medium complexity) was constructed. Comparison of different methodologies to remove regional trends revealed that the most effective algorithms are the bilinear saddle and local polynomial regressions. The use of these methods to analyze gravity data observed in the complex geological environments of the Ghor Al-Haditha site (eastern coastline of the Dead Sea, Jordan) successfully removed the regional gradient and localized the negative anomaly possibly produced by a subsurface sinkhole. The $3 \mathrm{D}$ gravity field modeling led to identification of the parameters of this $P G M$.

\section{Acknowledgments}

The authors would like to thank anonymous reviewers, who thoroughly reviewed this paper, and their critical comments and valuable suggestions were very helpful in preparing this paper. This publication was made possible through support provided by the U.S. Agency for International Development (USAID) and the MERC Program under terms of Award No. M27-050.

\section{References}

[1] L. V. Eppelbaum, M. G. Ezersky, A. S. Al-Zoubi, V. I. Goldshmidt, and A. Legchenko, "Study of the factors affecting the karst volume assessment in the Dead Sea sinkhole problem using microgravity field analysis and 3-D modeling," Advances in Geosciences, vol. 19, pp. 97-115, 2008.

[2] G. C. Colley, "The detection of caves by gravity measurements," Geophysical Prospecting, vol. 11, no. 1, pp. 1-9, 1963.

[3] Arzi, "Microgravimetry for engineering applications," Geophysical Prospecting, vol. 23, no. 3, pp. 408-425, 1975.

[4] Z. J. Fajklewicz, "Gravity vertical gradient measurements for the detection of small geologic and anthropogenic forms," Geophysics, vol. 41, no. 5, pp. 1016-1030, 1976.

[5] M. Blížkovský, "Processing and applications in microgravity surveys," Geophysical Prospecting, vol. 27, no. 4, pp. 848-861, 1979.

[6] M. Bichara, J. C. Erling, and J. Lakshmanan, "Technique de mesure et d'interpretation minimisant les erreurs de mesure en microgravimetrie," Geophysical Prospecting, vol. 29, pp. 782789, 1981.

[7] D. K. Butler, "Interval gravity-gradient determination concepts," Geophysics, vol. 49, no. 6, pp. 828-832, 1984.

[8] D. K. Butler, "Microgravimetric and gravity-gradient techniques for detection of subsurface cavities," Geophysics, vol. 49, no. 7, pp. 1084-1096, 1984.

[9] B. E. Khesin, V. V. Alexeyev, and L. V. Eppelbaum, "Investigation of geophysical fields in pyrite deposits under mountainous 
conditions," Journal of Applied Geophysics, vol. 30, no. 3, pp. 187204, 1993.

[10] D. Patterson, J. C. Davey, A. H. Cooper, and J. K. Ferris, “The investigation of dissolution subsidence incorporating microgravity geophysics at Ripon, Yorkshire," Quarterly Journal of Engineering Geology, vol. 28, no. 1, pp. 83-94, 1995.

[11] D. E. Yule, M. K. Sharp, and D. K. Butler, "Microgravity investigations of foundation conditions," Geophysics, vol. 63, no. 1, pp. 95-103, 1998.

[12] N. C. Crawford, "Microgravity investigations of sinkhole collapses under highway," in Proceedings of the 1st SAGEEP Conference, vol. 1, pp. 1-13, St. Louis, Mo, USA, 2000.

[13] M. Beres, M. Luetscher, and R. Olivier, "Integration of groundpenetrating radar and microgravimetric methods to map shallow caves," Journal of Applied Geophysics, vol. 46, no. 4, pp. 249$262,2001$.

[14] D. K. Butler, "Potential fields methods for location of unexploded ordnance," Leading Edge, vol. 20, no. 8, pp. 890-895, 2001.

[15] M. Rybakov, V. Goldshmidt, L. Fleischer, and Y. Rotstein, "Cave detection and 4-D monitoring: a microgravity case history near the Dead Sea," Leading Edge, vol. 20, no. 8, pp. 896-900, 2001.

[16] T. Hunt, M. Sugihara, T. Sato, and T. Takemura, "Measurement and use of the vertical gravity gradient in correcting repeat microgravity measurements for the effects of ground subsidence in geothermal systems," Geothermics, vol. 31, no. 5, pp. 525-543, 2002.

[17] L. V. Eppelbaum and B. E. Khesin, "Advanced 3D modelling of gravity field unmasks reserves of a pyrite-polymetallic deposit: a case study from the Greater Caucasus," First Break, vol. 22, no. 11, pp. 53-56, 2004.

[18] P. Styles, S. Toon, E. Thomas, and M. Skittrall, "Microgravity as a tool for the detection, characterization and prediction of geohazard posed by abandoned mining cavities," First Break, vol. 24, no. 5, pp. 51-60, 2006.

[19] D. K. Butler, Ed., Near-Surface Geophysics, no. 13 of Investigations in Geophysics, Society of Exploration Geophysicists, 2005.

[20] J. S. da Silva and F. J. F. Ferreira, "Gravimetry applied to water resources and risk management in karst areas: a case study in Parana state, Brazil," in Proceedings of the Transactions of the 23th FIG Congress, p. 14, Munich, Germany, 2006.

[21] M. W. Branston and P. Styles, "Site characterization and assessment using the microgravity technique: a case history," Near Surface Geophysics, vol. 4, no. 6, pp. 377-385, 2006.

[22] N. Debeglia, A. Bitri, and P. Thierry, "Karst investigations using microgravity and MASW; application to Orléans, France," Near Surface Geophysics, vol. 4, no. 4, pp. 215-225, 2006.

[23] I. R. Abad, F. G. García, I. R. Abad et al., "Non-destructive assessment of a buried rainwater cistern at the Carthusian Monastery "Vall de Crist" (Spain, 14th century) derived by microgravimetric 2D modelling," Journal of Cultural Heritage, vol. 8, no. 2, pp. 197-201, 2007.

[24] C. C. Bradley, M. Y. Ali, I. Shawky, A. Levannier, and M. A. Dawoud, "Microgravity investigation of an aquifer storage and recovery site in Abu Dhabi," First Break, vol. 25, no. 11, pp. 63-69, 2007.

[25] L. V. Eppelbaum, "Revealing of subterranean karst using modern analysis of potential and quasi-potential fields," in Proceedings of the SAGEEP Conference, vol. 20, pp. 797-810, Denver, Colo, USA, 2007.
[26] T. Mochales, A. M. Casas, E. L. Pueyo et al., "Detection of underground cavities by combining gravity, magnetic and ground penetrating radar surveys: a case study from the Zaragoza area, NE Spain," Environmental Geology, vol. 53, no. 5, pp. 1067-1077, 2008.

[27] S. Deroussi, M. Diament, J. B. Feret, T. Nebut, and T. Staudacher, "Localization of cavities in a thick lava flow by microgravimetry," Journal of Volcanology and Geothermal Research, vol. 184, no. 1-2, pp. 193-198, 2009.

[28] M. Ezersky, A. Legchenko, C. Camerlynck et al., “The Dead Sea sinkhole hazard-new findings based on a multidisciplinary geophysical study," Zeitschrift fur Geomorphologie, vol. 54, no. 2, pp. 69-90, 2010.

[29] F. Greco, G. Currenti, C. Del Negro et al., "Spatiotemporal gravity variations to look deep into the Southern flank of Etna volcano," Journal of Geophysical Research B, vol. 115, no. 11, Article ID B11411, 2010.

[30] G. Leucci and L. de Giorgi, "Microgravimetric and ground penetrating radar geophysical methods to map the shallow karstic cavities network in a coastal area (Marina Di Capilungo, Lecce, Italy)," Exploration Geophysics, vol. 41, no. 2, pp. 178-188, 2010.

[31] A. G. Camacho, P. J. González, J. Fernández, and G. Berrino, "Simultaneous inversion of surface deformation and gravity changes by means of extended bodies with a free geometry: application to deforming calderas," Journal of Geophysical Research, vol. 116, no. B10, 2011.

[32] L. V. Eppelbaum, "Review of environmental and geological microgravity applications and feasibility of their implementation at archaeological sites in Israel," International Journal of Geophysics, vol. 2011, Article ID 927080, 9 pages, 2011.

[33] A. Hajian, H. Zomorrodian, P. Styles, F. Greco, and C. Lucas, "Depth estimation of cavities from microgravity data using a new approach: the local linear model tree (LOLIMOT)," Near Surface Geophysics, vol. 10, pp. 221-234, 2012.

[34] L. V. Eppelbaum, "Application of microgravity at archaeological sites in Israel: some estimation derived from 3D modeling and quantitative analysis of gravity field," in Proceedings of the Symposium on the Application of Geophysics to Engineering and Environmental Problems Conference (SAGEEP), vol. 22, pp. 434446, Fort Wort, Tex, USA, 2009.

[35] K. J. Sjostrom and D. K. Butler, "Noninvasive weight determination of stockpiled ore through microgravity measurements," Report of the US Army Corps of Engineers, Paper GL-96-24, 1996.

[36] E. Elawadi, A. Salem, and K. Ushijima, "Detection of cavities and tunnels from gravity data using a neural network," Exploration Geophysics, vol. 32, no. 4, pp. 204-208, 2001.

[37] N. Debeglia and F. Dupont, "Some critical factors for engineering and environmental microgravity investigations," Journal of Applied Geophysics, vol. 50, no. 4, pp. 435-454, 2002.

[38] D. Carbone and F. Greco, "Review of microgravity observations at Mt. Etna: a powerful tool to monitor and study active volcanoes," Pure and Applied Geophysics, vol. 164, no. 1, pp. 122, 2007.

[39] T. Jacob, J. Chery, R. Bayer et al., “Time-lapse surface to depth gravity measurements on a karst system reveal the dominant role of the epikarst as a water storage entity," Geophysical Journal International, vol. 177, no. 2, pp. 347-360, 2009.

[40] G. Castiello, G. Florio, M. Grimaldi, and M. Fedi, "Enhanced methods for interpreting microgravity anomalies in urban areas," First Break, vol. 28, no. 8, pp. 93-98, 2010. 
[41] S. Porzucek, "Some Applicability problems of Euler deconvolution to the interpretation of the results of microgravity survey," in Proceedings of the Transactions of the Near Surface EAGE Conference, P55, pp. 1-5, Zurich, Switzerland, 2010.

[42] A. C. Dolgal and A. F. Sharkhimullin, "Increasing accuracy of monogenic gravity anomaly interpretation," Geoinformatics, vol. 4, pp. 49-56, 2011 (Russian).

[43] G. Kaufmann, D. Romanov, and R. Nielbock, "Cave detection using multiple geophysical methods: unicorn cave, Harz Mountains, Germany," Geophysics, vol. 76, no. 3, pp. B71-B77, 2011.

[44] J. Panisova, R. Pašteka, J. Papco, and M. Fraštia, “The calculation of building corrections in microgravity surveys using close range photogrammetry," Near Surface Geophysics, vol. 10, pp. 391-399, 2012.

[45] L. V. Eppelbaum, "Archaeological geophysics in Israel: past, present and future," Advances in Geosciences, vol. 24, pp. 45-68, 2010.

[46] B. E. Khesin, V. V. Alexeyev, and L. V. Eppelbaum, Interpretation of Geophysical Fields in Complicated Environments, Advanced Approaches in Geophysics, Kluwer Academic, Dordrecht, The Netherlands, 1996.

[47] W. M. Telford, L. P. Geldart, and R. E. Sheriff, Applied Geophysics, Cambridge University Press, Cambridge, UK, 1990.

[48] L. V. Eppelbaum and B. E. Khesin, Geophysical Studies in the Caucasus, Springer, Heidelberg, Germany, 2012.

[49] L. V. Eppelbaum, B. E. Khesin, and S. E. Itkis, "Archaeological geophysics in arid environments: examples from Israel," Journal of Arid Environments, vol. 74, no. 7, pp. 849-860, 2010.

[50] D. S. Parasnis, Principles of Applied Geophysics, Chapman \& Hall, London, UK, 4th edition, 1986.

[51] D. T. Sandwell and W. H. F. Smith, "Global marine gravity from retracked Geosat and ERS-1 altimetry: ridge segmentation versus spreading rate," Journal of Geophysical Research B, vol. 114, no. 1, Article ID B01411, 2009.

[52] A. Ginzburg and Z. Ben-Avraham, "A seismic refraction study of the north basin of the Dead Sea, Israel," Geophysical Research Letters, vol. 24, no. 16, pp. 2063-2066, 1997.

[53] M. Weber, K. Abu-Ayyash, A. Abueladas et al., "Anatomy of the Dead Sea transform from lithospheric to microscopic scale," Reviews of Geophysics, vol. 47, no. 2, 2010.

[54] M. J. Wichura, "Algorithm AS 241: the percentage points of the normal distribution," Applied Statistics, vol. 37, no. 3, pp. 477484, 1988.

[55] S. Shatterjee and A. S. Sadi, Regression Analysis by Example, John Wiley \& Sons, New York, NY, USA, 1996.

[56] J. O. Rawlings, S. G. Pantula, and D. A. Dickey, Applied Regression Analysis: A Research Tool, Springer, New York, NY, USA, 2nd edition, 1998.

[57] M. H. Bingham and J. M. Fry, Regression: Linear Models in Statistics, Undergraduate Math Series, Springer, London, UK, 2010.

[58] S. A. Taqieddin, N. S. Abderahman, and M. Atallah, "Sinkhole hazards along the eastern Dead Sea shoreline area, Jordan: a geological and geotechnical consideration," Environmental Geology, vol. 39, no. 11, pp. 1237-1253, 2000.

[59] A. Al-Zoubi, A. Abueadas, A. Akkawwi, L. Eppelbaum, E. Levi, and M. Ezersky, "Use of microgravity survey in the Dead Sea areas affected by the sinkholes hazard," in Proceedings of the Transactions of the 8th EUG Meeting, Geophysical Research Abstracts, vol. 14 of EGU2012-1982, Vienna, Austria, 2012. 

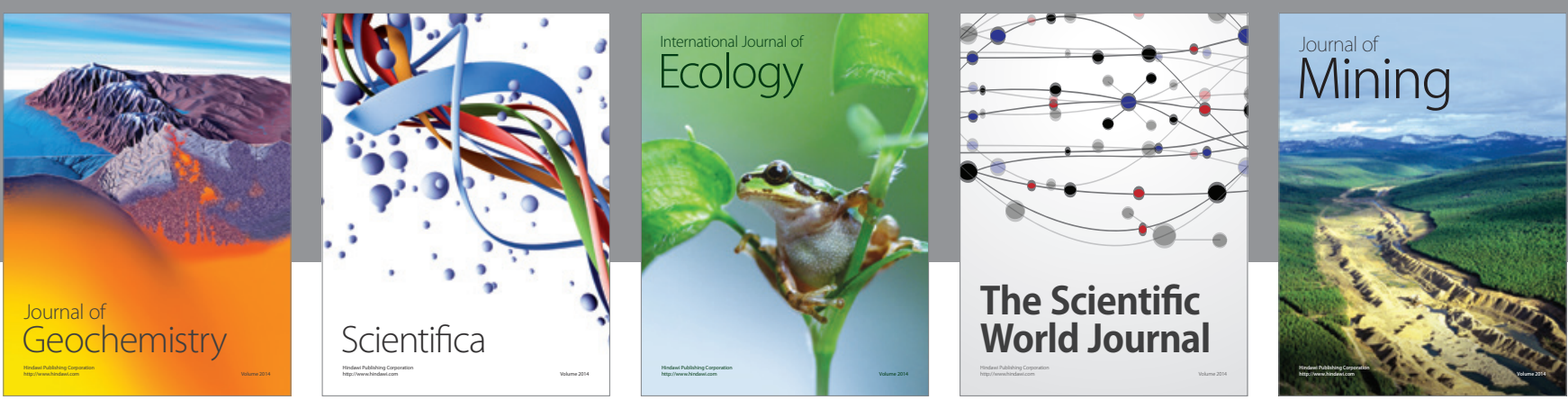

The Scientific World Journal
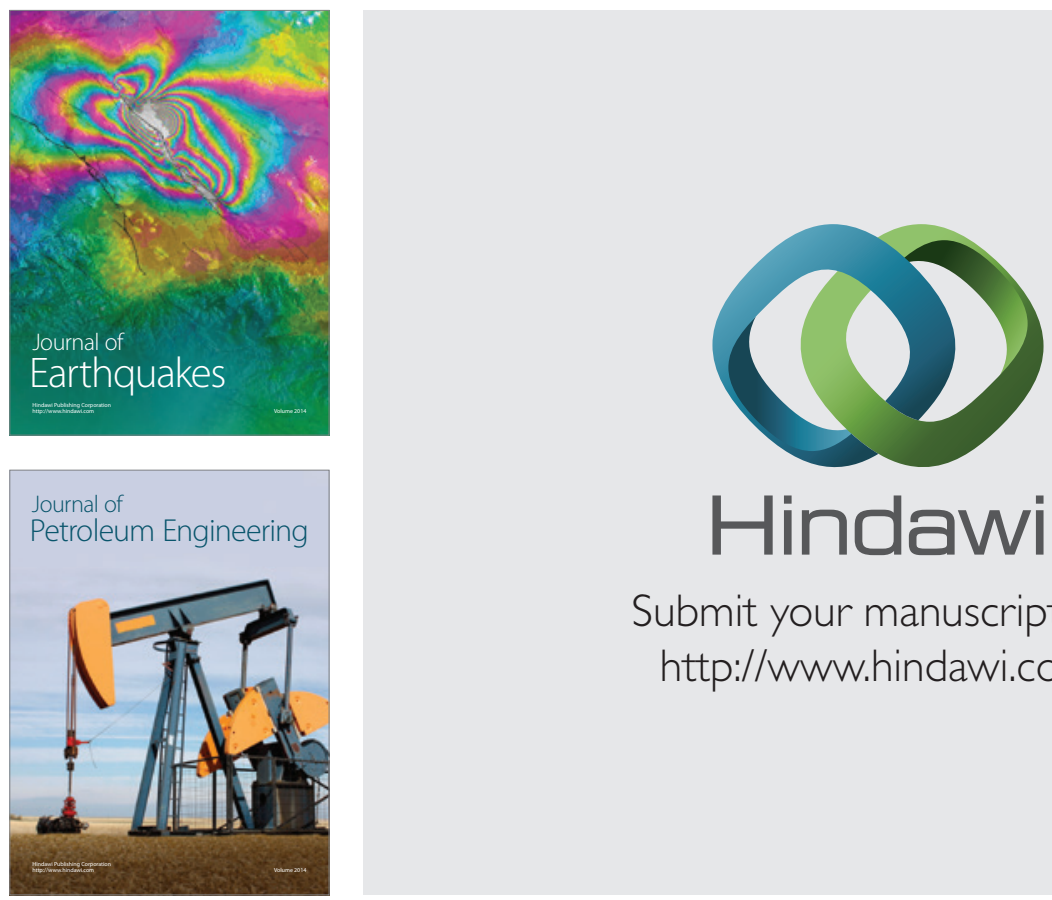

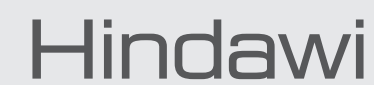

Submit your manuscripts at

http://www.hindawi.com
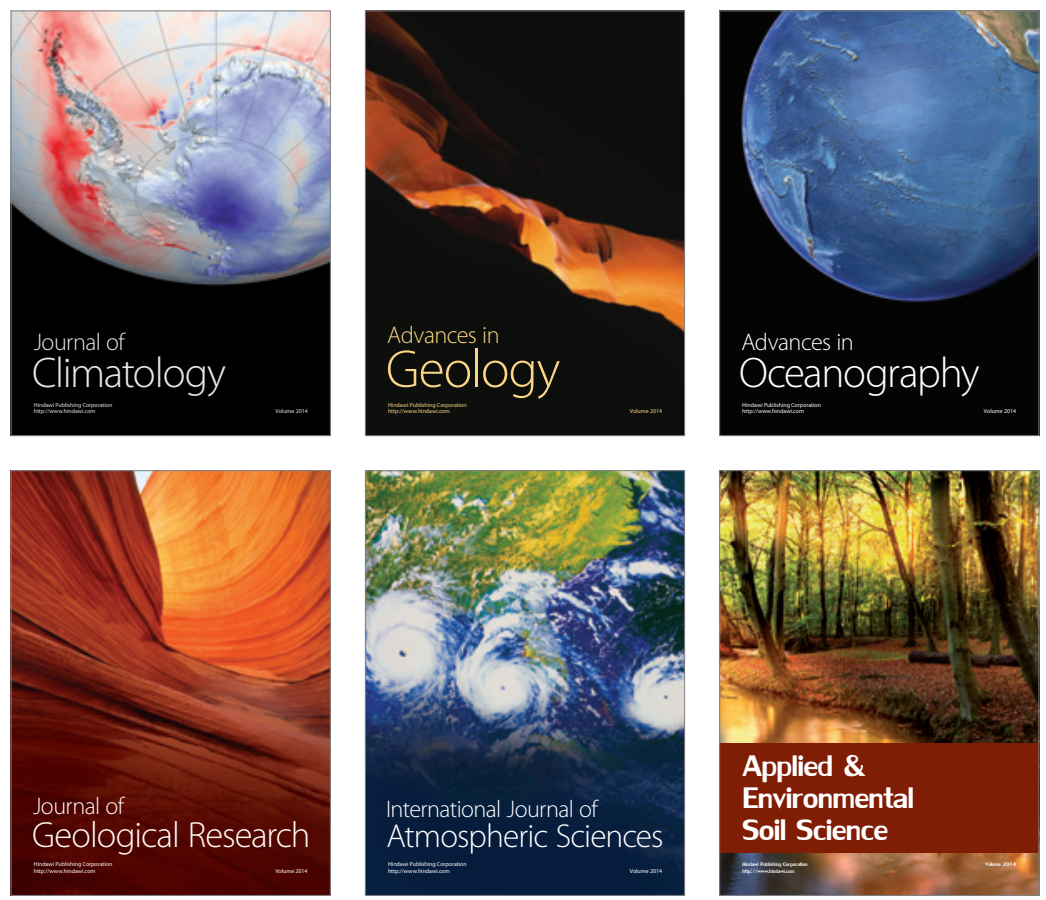
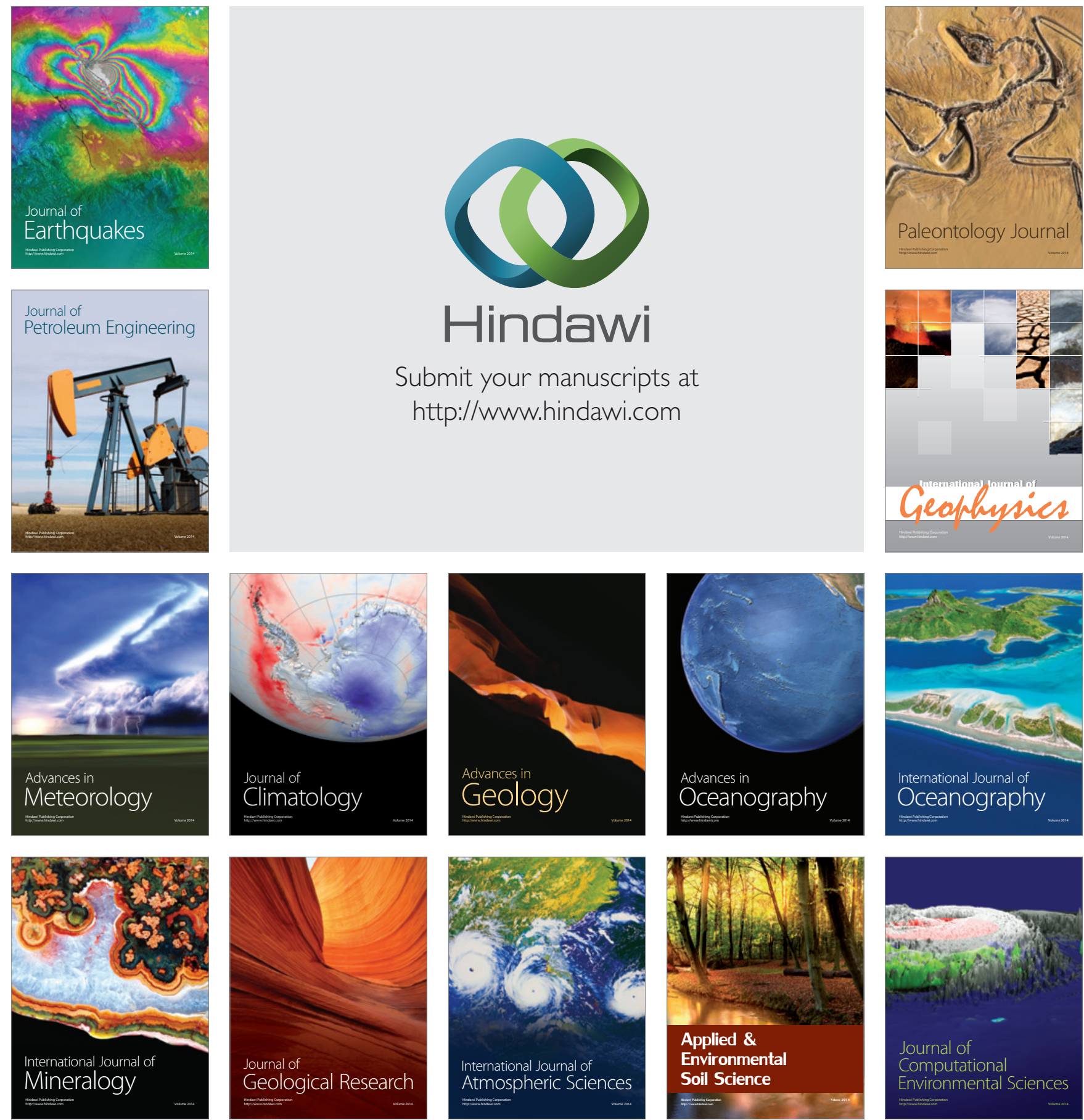